\title{
Comparative analysis of methods and model prediction performance evaluation for continuous online non-invasive quality assessment during drying of apples from two cultivars
}

\author{
Luna Shrestha ${ }^{\mathrm{a}, *}$, Stuart O.J. Crichton ${ }^{\mathrm{a}}$, Boris Kulig ${ }^{\mathrm{a}}$, Bernadette Kiesel ${ }^{\mathrm{a}}$, Oliver Hensel $^{\mathrm{a}}$, \\ Barbara Sturm $^{\mathrm{a}, \mathrm{b}}$
}

${ }^{a}$ Department of Agricultural and Biosystems Engineering, University of Kassel, Witzenhausen, Germany

${ }^{\mathrm{b}}$ School of Natural and Environmental Sciences, Newcastle University, Newcastle upon Tyne, UK

\section{A R T I C L E I N F O}

\section{Keywords:}

PLS

Method comparison

Variable Importance in projection (VIP)

Vis/NIR hyperspectral imaging system

Dried apple slices

\begin{abstract}
A B S T R A C T
Quality attributes such as moisture content, colour parameters and shrinkage of apples change undesirably during the drying process. Drying is a highly dynamic process, thus, an effective optimisation in terms of product quality and process performance requires continuous non-invasive measurement of the parameters in question. In this study, visual to near infra-red hyperspectral imaging was used in combination with the respective gold standard methods to estimate moisture ratio, CIELab chromaticity, browning index, shrinkage, and rehydration ratio of apple slices during the hot air-drying process. Two varieties (cv. Elstar and Golden delicious) of apples at three slice thicknesses $(2,3$, and $4 \mathrm{~mm})$ were dried at $60^{\circ} \mathrm{C}$ and $70^{\circ} \mathrm{C}$. Prediction models for the space-averaged spectral reflectance curves were built using the partial least square regression method and including both varieties. The performance of moisture ratio prediction was excellent (adj $\mathrm{R}^{2}=0.94$, RMSEP $=0.076$ ) and the Variable Importance in the Projection value cut off above 0.8 at $970 \mathrm{~nm}$ and $\mathrm{L}^{*}$ at $685 \mathrm{~nm}$. Similarly, partial least square regression modelling showed a good prediction for $\mathrm{a}^{*}, \mathrm{~b}^{*}$ value, BI, shrinkage and acceptable prediction for $L^{*}$ and RR. The model performance was robust to the system settings irrespective of slice thickness, drying temperature and apple variety. Additionally, method comparisons using Bland-Altman, Bablok, and Deming regression were performed. The results confirm that the compared destructive (laboratory gold standard) and non-destructive hyperspectral methods can be interchangeably used within the limit of agreement $( \pm 1.96$ standard deviations) and precision for determination of the MR, CIELAB chromaticity and BI, shrinkage, and rehydration ratio. Therefore, these results confirm that hyperspectral imaging system can be used in online monitoring of the apples during the drying process, and thus, in the optimisation of product and process performance quality attributes.
\end{abstract}

\section{Introduction}

According to the World Health Organisation (WHO), approximately 3.9 million deaths worldwide were attributable to inadequate fruit and vegetable (F \& V) consumption in 2017 [1]. Inadequacy of consumptionof $\mathrm{F} \& \mathrm{~V}$ leads to poor health and several diseases such as cardiovascular diseases and certain types of cancer. Thus, the recognition of the importance of a healthy lifestyle has driven many consumers toward increasing their fruits and vegetables intake. With rising incomes and the increasing awareness towards food and its quality, consumers have developed different consumption patterns and as a result the demand for dried fruits and vegetables has risen amongst others because of time efficiency and convenience [2]. Drying of fruits is one of the oldest preservation methods. Dried apples for instance have become a popular convenient snack with high nutritional value, and are one of the major constituents of this changed nutrition pattern

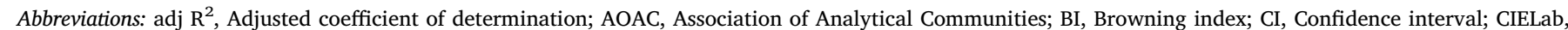

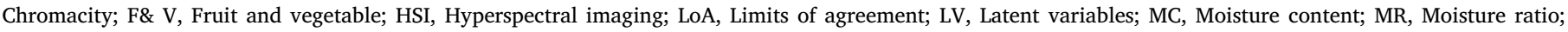

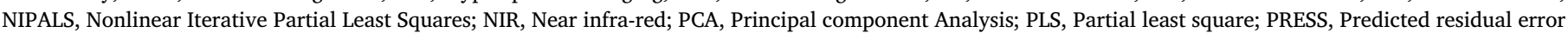

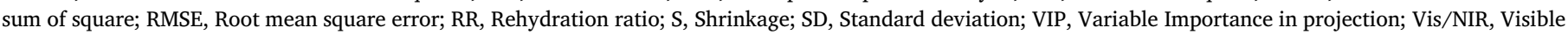
to near infra-red; WHO, World Health Organization

* Corresponding author.

E-mail addresses: sthaluna@gmail.com,uk027586@student.uni-kassel.de (L. Shrestha). 
$[3,4]$. These dried products can be useful as main ingredients or secondary raw materials such as apple ring snacks or to produce energy fruit bars [5]. Additionally, dried fruits and vegetables have a longer shelf life compared to fresh fruits, higher total energy per Kilocalorie, product diversity and substantial volume reduction with the incorporation of proper improvements in product quality and process applications [6]. The knowledge of physicochemical and quality properties of dried apples could increase the current degree of acceptance of dehydrated foods in the market. Nonetheless, drying of fruits may lead to undesirable changes in physical and chemical properties such as colour loss, change in shape and size that may lead to a decrease in consumers' acceptance and market value. Noteworthy, buying behaviour of consumers is often related to external attributes such as the colour or appearance [7]. These have become significant quality parameters in consumer perception of dried apple quality. Therefore, food industry has been seeking accurate on-line processing technologies that optimize the drying conditions for obtaining high quality dried products, meeting the quality requirements demanded by the market $[8,9]$. Thus, there is a crucial requirement of fast interventions in quality assessment in case of any deviation from the specified course of the process such as different types of apple varieties, slice thickness and drying temperatures. The complexity of drying is due to interrelation between the phenomena of heat and moisture transfer. Many of these are functions of moisture content, drying time and colour changes [10]. Besides these parameters, apple cultivars also contribute to the variation in end-product quality. Additionally, different apple cultivars differ in moisture content, porosity and chemical composition which has also the greatest influence on the quality defining characteristics of dried products [11-13]. Furthermore, the standard laboratory techniques, such as the gravimetric method for moisture content determination, the colour parameter by using Chromameter, interrupt a continuous drying processing because they are invasive, often destructive, costly and timeintensive. Thus, there is a great need for non-destructive non-invasive measurement technique to determine these core quality attributes in a continuous drying process [14-19]. A recent trend in the food drying research focuses on the development of smart drying technology (artificial intelligence, computer vision, visible (Vis) and near-infrared (NIR) spectroscopy, magnetic resonance imaging, and control system for the drying environment) to meet high requirements on product quality. The emerging intelligent control drying technologies offer improvement in food quality by minimizing thermal degradation, time of drying and minimal changes in nutritional and aesthetical value [20]. For instance: non-invasive techniques, i.e. hyperspectral imaging (HSI) for real-time observation of multiple product quality attributes, such as moisture content, shrinkage, porosity, density, colour, and texture, as well as valuable components have been reported [21]. Martynenko and Sturm [22] reported intelligence in the form of computer vision and soft sensors will cover existing gaps in knowledge regarding process-product interactions and product quality transformation within the process of drying. The acquired information is used in control strategies, facilitating adaptive (multivariate) control and thus, generating intelligent drying systems. Thus, these systems will be helpful for the drying industry for optimization via online and inline non-destructive monitoring of product quality metrics and simultaneously controlling the process operation by integrating the feedback from such a monitoring system [23].

Moreover, it is imperative for the food industry that all food quality instruments are precise and accurate. These food quality attributes such as moisture content, colour parameters during drying are measured using a laboratory destructive (or at least interruptive) approach which has been commonly used for decades. Currently, there is a trend towards replacing these destructive methods by numerous non-invasive techniques such as HSI in the visible and Near-Infrared (Vis/NIR) ranges, Raman spectroscopy, and Magnetic resonance imaging to analyse the quality attributes during the drying process [24]. These techniques are gaining more importance in laboratory and online quantitative applications for industrial use due to their characteristics such as quickness, reproducibility of measurements requiring no sample preparation, the robustness of the equipment and the possibility to study the distribution of the different quality attributes within a sample.

The basic principle of HSI is to accumulate data on light reflected, scattered, absorbed by a sample from across the electromagnetic spectrum (ultraviolet, near-infrared and infrared regions) that are not detectable by the human eyes [25]. The HSI system produces electromagnetic energy in different forms at particular wavelengths according to the differences in food quality. It combines spectroscopy and digital imaging which provides both spectral and spatial information from an object. The spectral features provide a wide range of multi-constituent surface and subsurface characteristics and the spatial features of HSI elaborate a complex heterogeneous sample [26].

Detection failures of quality attributes may lead to critical issues in the current market and loss of economic value [27]. Therefore, robust and accurate statistical methods are required for proper evaluations of all analysis in order to validate the new approach. Various statistical approaches have been used to assess the accuracy of the new techniques to avoid the inappropriate conclusion [28]. Different partial least square (PLS) regression models have been developed to determine the performance of new techniques. The oldest criteria for measuring agreement are the correlation coefficient (r). However, it is also important to be sure that a new method of measurement is in the agreement with the current or gold standard (laboratory) method. The correlation coefficient seems to be inappropriate as correlation only measures the strength of linear association between variables [29]. Bland and Altman stated that it is very unlikely of two different methods or instrument to be exactly in agreement or to give identical results for all individuals. The Bland-Altman method is the approach most commonly used to assess the agreement between the two measurement methods [30]. It determines the mean difference between two methods of measurement (the bias) and $95 \%$ limits of agreement as to the mean difference [1.96 standard deviations (SD)]. The method is based on the fact that when there is a non-consistent systematic bias between two measurement systems, the correlation between the mean of two measurement systems and the mean difference between two methods of measurement is zero and a horizontal regression line fits the points in the plot. If the slope of the regression line fitted to the Bland-Altman plot is not significantly different from zero then the proportional bias is absent [31].

To date no scientific work has been published related to the models prediction performance analysis for continuous online non-invasive quality assessment during drying of apples from two cultivars. Furthermore, no performance comparison between destructive analytical approaches (gold standard) and a non-destructive (HSI) method by using various regression methods such as Bland-Altman and Bablok regression has been reported. Sturm, [32] reported there is variation in moisture content and structure of slices within the individual apple of one variety. However, the fluctuations within the apple remain in a very narrow range. Additionally, different levels of porous structure are present in apple. Joardder et al., [33] showed that dried Granny Smith apple has a higher porosity due to its larger cell dimensions and the consequent loose packing of cells compared to Red Delicious. In this framework, the main objective of this study was to build robust prediction models for hyperspectral imaging that are valid across two apple varieties and independent of slice thickness and drying conditions to visualize quality parameters such as moisture content, CIELab colour parameters, browning index (BI), shrinkage (S) and rehydration ratio (RR). The specific objectives were to (i) to establish an HSI system in the spectral range of $400-1010 \mathrm{~nm}$ to acquire the hypercubes of apple samples, (ii) to extract spectral information and identify the significant wavebands based on the Variable Importance in projection Plots (VIP) and to determine important latent factors which then were used to develop the PLSR models, (iii) to develop the PLS regression model and prediction of MR, colour attribute such as $\mathrm{L}^{*}, \mathrm{a}^{*}, \mathrm{~b}^{*}, \mathrm{BI}$, shrinkage and 


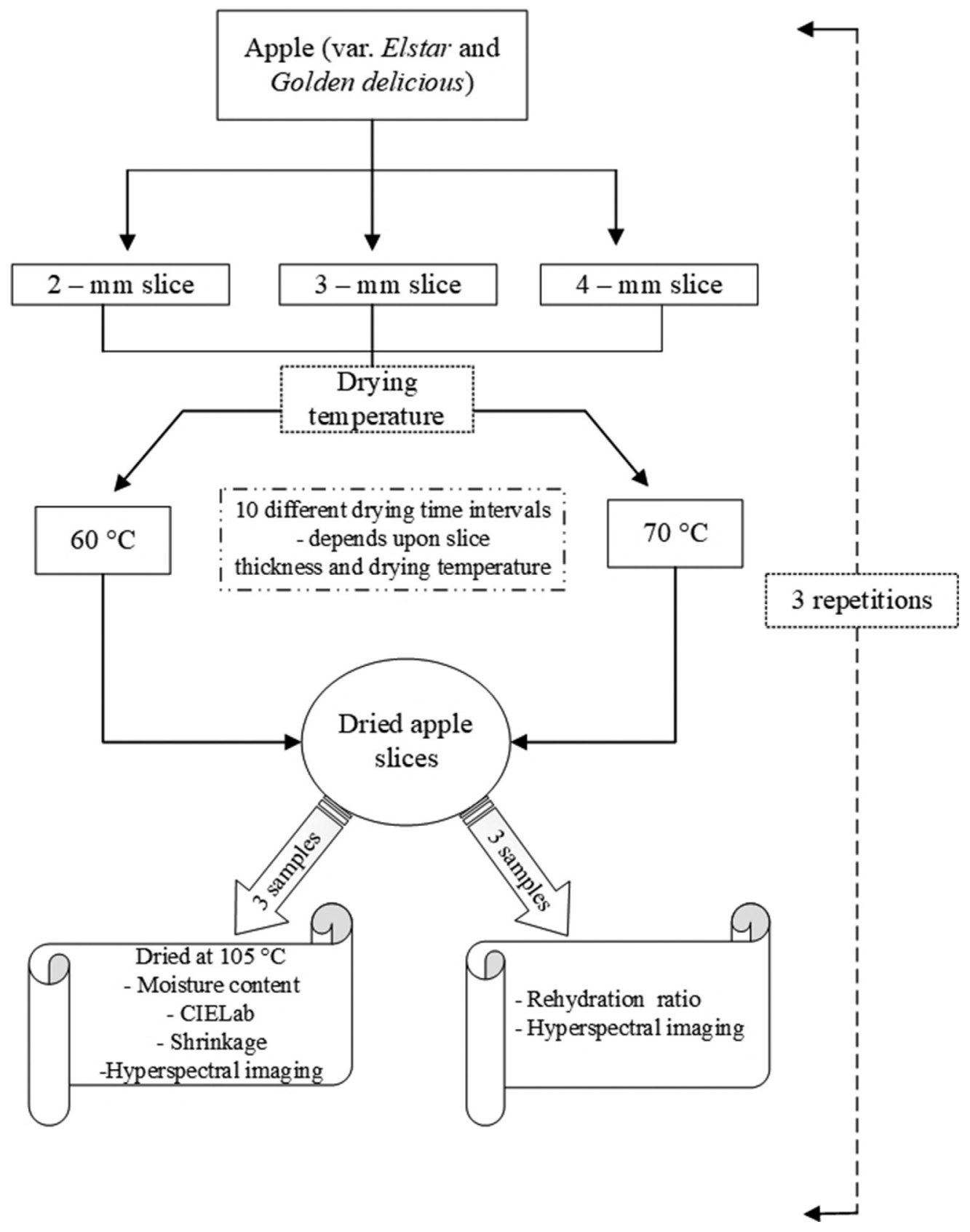

Fig. 1. Diagram of the experimental design.

rehydration ratio in apple slices, and (iv) to evaluate the agreement between the results obtained by HSI and the laboratory assessment during the drying of apple slices independent of different setting parameters (two different apple varieties, two drying temperature setting and three slice thickness).

\section{Material and methods}

\subsection{Overview of the experimental design}

Fig. 1 gives an overview of the experimental design. A three-factor, general factorial design was developed to systematically study the influence of the factors: apple cultivar (cv. Elstar and Golden delicious), drying temperature $\left(60^{\circ} \mathrm{C}\right.$ and $\left.70^{\circ} \mathrm{C}\right)$, slice thickness $(2 \mathrm{~mm}, 3 \mathrm{~mm}$, and $4 \mathrm{~mm}$ ) on drying time, CIELab colour parameter, BI, shrinkage and rehydration ratio during drying processing. The general factorial design allows to have factors with a different number of levels and create an experiment that includes all possible combinations of factor levels. The experimental design was augmented by three replicate runs of all factors. Three replications were performed for each experiment to get a true average of the data which help to reduce the measurement errors and also to increase the number of samples that helps to develop a robust model.

\subsubsection{Sample preparation}

Apples (cv. Elstar and Golden delicious) from the same lot each were purchased from the local supermarket in Witzenhausen, Germany. Golden delicious apples were source from Italy and Elstar apples were source from Germany. The samples were stored at $4 \pm 1{ }^{\circ} \mathrm{C}$ until processing. Fruit sampling was performed by randomly selecting sound apples from the batch, with uniform size and ripening stage. Samples were stored at room temperature for $2 \mathrm{~h}$ before starting the experimental activities. Apples were washed, cored using a $25 \mathrm{~mm}$ apple stainless corer (Lurch, Hildesheim, Germany) and sliced into discs 
( $2 \mathrm{~mm}, 3 \mathrm{~mm}$, and $4 \mathrm{~mm}$ thick) using an electric slicing machine (Graef, Allesschneider Vivo V20, Arnsberg, Germany). Finally, to prepare slices of uniform outer diameter $(62 \mathrm{~mm})$ a circular cookies cutter (Flammable, Germany) was used as presented in Fig. 1.

360 apple slices were prepared based on drying parameters (variety, temperature, thickness) investigated, randomly arranged into 36 batches of 30 samples and subjected to hot-air drying. Additionally, 108 apple slices were prepared for rehydration ratio determination.

\subsubsection{Drying experiments}

Drying experiments were performed by warming up the dryer for $30 \mathrm{~min}$ for stabilizing the required air temperature and then consecutive apple slices drying was performed at set conditions. At $60^{\circ} \mathrm{C}$ drying temperature, $2 \mathrm{~mm}$ samples were subjected to $5 \mathrm{~h}$ hot air drying and sampling was performed at $0,15,30,60,90,120,150,180,240$, $300 \mathrm{~min} ; 3 \mathrm{~mm}$ samples were subjected to $6 \mathrm{~h}$ hot air drying and sampling was performed at $0,15,30,60,90,120,180,240,300,360 \mathrm{~min}$; $4 \mathrm{~mm}$ samples were subjected to $7 \mathrm{~h}$ hot air drying and sampling was performed at $0,15,30,60,120,180,240,300,360,420 \mathrm{~min}$. At $70{ }^{\circ} \mathrm{C}$ drying temperature, $2 \mathrm{~mm}$ samples were subjected to $4 \mathrm{~h}$ hot air drying and batch sampling was performed at $0,15,30,60,90,120,150,180$, 210, $240 \mathrm{~min} ; 3 \mathrm{~mm}$ samples were subjected to $5 \mathrm{~h}$ hot air drying and batch sampling was performed at $0,15,30,60,90,120,150,180,240$, $300 \mathrm{~min} ; 4 \mathrm{~mm}$ samples were subjected to $6 \mathrm{~h}$ hot air drying and batch sampling was performed at $0,15,30,60,90,120,180,240,300$, 360 min.

\subsubsection{Reference measurements}

The moisture contents of the apple slices were obtained from the gravimetric method during the drying process as shown in the Fig. 1. The average value of the triplicate experiments was determined. After the drying process, the samples were dried at $105^{\circ} \mathrm{C}$ in an hot air oven (SLE 500, Memmert GmbH, Germany) for $24 \mathrm{~h}$ according to Association of Analytical Communities (AOAC) [34] to determine the final moisture content. Moisture content (MC, wet base) was determined from the weighing with initial and final moisture determination. The moisture ratio (MR) was calculated with Eq. (1) below:

$\mathrm{MR}=\frac{M-M_{e}}{M_{i}-M_{e}}$

with $M$ as moisture content at any time, $M_{i}$ as the initial moisture content and $M_{e}$ as the equilibrium moisture content. According to [35], it was simplified to equation (2) below:

$\mathrm{MR}=\frac{M}{M_{i}}$

Colour of apple slices was measured on the upper surface of each sample by performing four colour measurement on opposite sides of each slice. The three colour components in $L^{*} a^{*} b^{*}$ space were determined with a hand tristimulus reflectance colorimeter (CR-400, Konica Minolta, Osaka, Japan). Before colour acquisition, the colorimeter was calibrated using a standard white plate. $L^{*}$ represent the brightness component of samples. The higher the $\mathrm{L}^{*}$ value, the brighter the sample. The value of $a^{*}$ is the ratio between red and green, the higher the value the redder is the sample and the lower the value, the greener is the sample. The value of $b^{*}$ is the ratio between yellow and blue. The higher the value, the sample is yellower and the lower the value, the sample is bluer in colour. The changes in each individual colour parameters were calculated as Equation (3)

$\Delta L^{*}=L^{*}-L_{0}^{*} ; \Delta a^{*}=a^{*}-a_{0}^{*} ; \Delta b^{*}=b^{*}-b_{0}^{*}$

The subscript ' 0 ' refers to the initial colour parameters of each sample at the beginning of the drying experiments.

According to Bußler, Ehlbeck, \& Schlüter, [36] BI was calculated as Equation (4)
$\mathrm{BI}=\frac{[100(\mathrm{x}-0.31)]}{0.17}$

where,

$\mathrm{x}=\frac{\left(\mathrm{a}^{*}+1.75 \mathrm{~L}^{*}\right)}{5.645 \mathrm{~L}^{*}+\mathrm{a}^{*}-3.012 \mathrm{~b}^{*}}$

Relative shrinkage of the samples during drying was expressed in terms of relative change in volume as the sample volume at any time (V) to initial volume $\left(\mathrm{V}_{0}\right)$ [37] as Equation (5). The volume was calculated by measuring the height at three points of each slices by using a calliper $0-150 \mathrm{~mm}$ (Kinzo) at every measuring interval and two-dimensional shrinkage (changes in slice area) was determined by counting pixels retrieved from HSI.

Shrinkage $(\mathrm{S})=\frac{\mathrm{V}(\text { area } * \text { height })}{\operatorname{Vo}(\text { areafresh } * \text { heightfresh })}$

Rehydration experiments were performed by immersing a weighed dried sample into $300 \mathrm{ml}$ distilled water at $65^{\circ} \mathrm{C}$ for $10 \mathrm{~min}$ at $100 \mathrm{rpm}$ on a magnetic heat stirrer mod. RMH (Gehardt GmBH \& Co. KG, Königswinter, Germany). The samples were drained over a mesh for two minutes followed by gently blotting with paper tissue 3-4 times in order to absorb and eliminate the adhering surface water and then reweighed. Triplicate experiments were carried out for each setting. Rehydration ratio (RR) was measured as the weight of sample after rehydration to the weight before drying as shown

$\mathrm{RR}=\frac{\mathrm{W}_{\text {rehydrated }}}{\mathrm{W}_{\text {initial }}}$

\subsection{Overview of hyperspectral data processing and analysis}

A flowchart (Fig. 2) is used to give a general overview of the methodology. In this study, a two-step validation approach was followed for the model development: (i) cross validation of the whole data sets and (ii) randomly splitting data to an independent test data set.

\subsubsection{Hyperspectral image acquisition, image segmentation and pre-} processing

A hyperspectral imaging system type ImSpector V10E (Specium Spectral Imaging Ltd, Finland) was used to acquire scanning images of the apple slices. The system was comprised of an illumination source (three $60 \mathrm{~W}$ halogen lamps) fixed at a $45^{\circ}$ angle to illuminate the samples, a linear translation stage, and the hyperspectral imager coupled with a $35 \mathrm{~mm}$ Schneider lens C-mount zoom lens (Xenoplan 1.9/ 35, Schneider Optishce Werk GmbH, Germany). The distance between the camera lens and the surface of the apple slices was fixed at $270 \mathrm{~mm}$. The HSI system measures a set of three sample slices at a time in the reflected wavelengths from 400 to $1010 \mathrm{~nm}$. However, the wavelength region between 491 and $1005 \mathrm{~nm}$ was used in this study due to the low output of the illumination system in the lower wavelength region. The samples were scanned at a moving speed of $8 \mathrm{~mm} \mathrm{~s}^{-1}$; images were consequently captured by the camera at intervals of $1.5 \mathrm{~nm}$ and the exposure time was set at $20 \mathrm{msec}$. Each complete image consisted of 3 apple slices and the white reference tile. A white tile of $200 \mathrm{~mm} \times 24 \mathrm{~mm}(\mathrm{H} \times \mathrm{W})$ was used as a reference which resulted in a spatial resolution of $1700 \times 1392$ pixels $(\mathrm{H} \times \mathrm{W})$. The apple samples were saved in ENVI 3.6 format (Research system, Inc., USA) for further processing.

Both white and dark references were acquired to correct the raw images by excluding the random noise (such as uneven light source intensities). The dark reference was obtained by closing the shutter of the camera. Image segmentation, background and dead pixel removal, noise removal and average reflectance calculation were carried out using Matlab 2015a, following the methods used in a previous study [38]. The relative reflectance spectrum for each pixel in the image $(R$ 


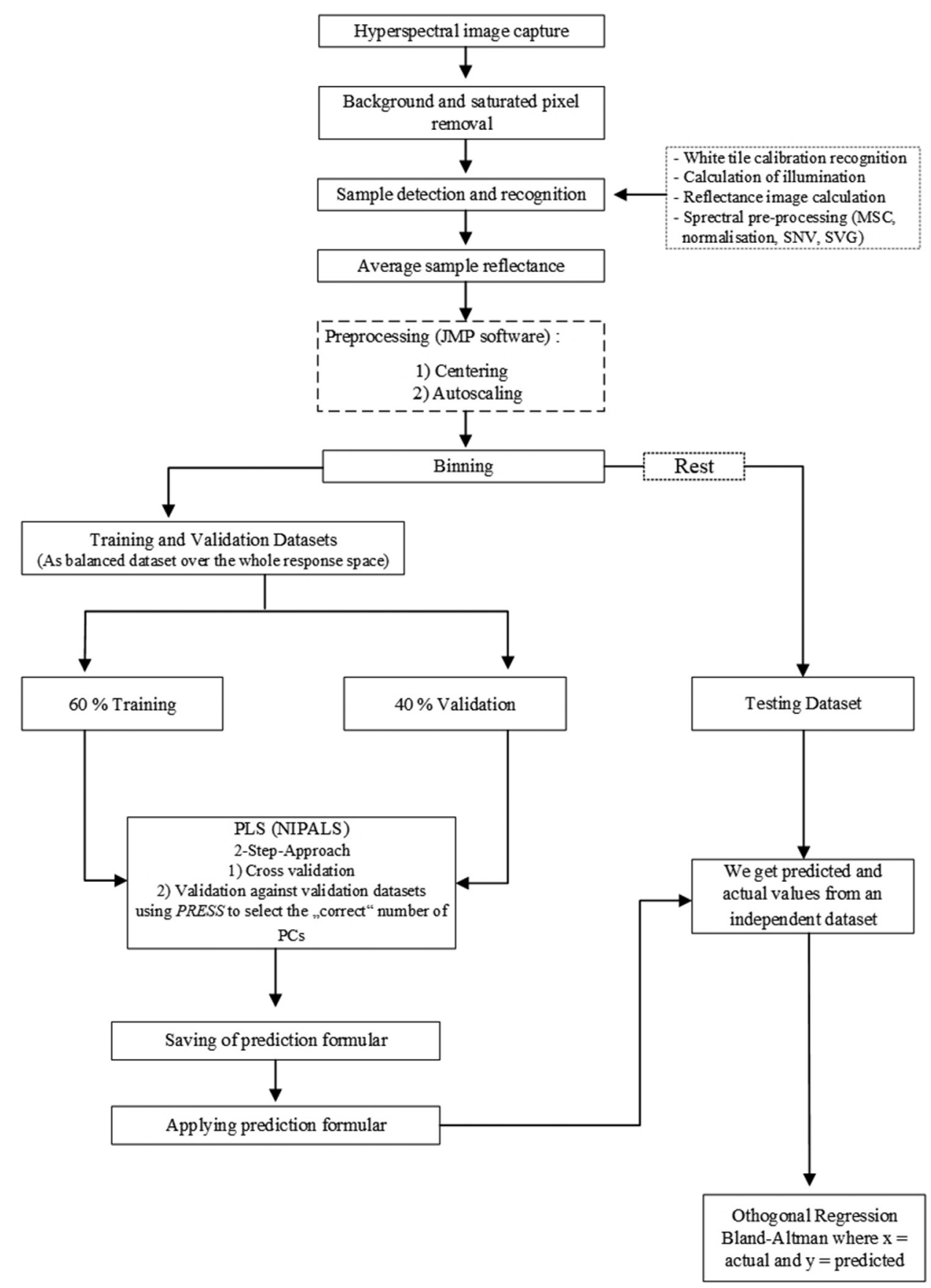

Fig. 2. Flowchart showing a general overview for each hyperspectral image and data processing methodology.

$\left.\left(\lambda_{x y}\right)\right)$ was calculated with the following equation with spatially averaged reference illumination spectrum $W\left(\lambda_{x y}\right)$ and the sample irradiance spectrum $S\left(\lambda_{x y}\right)$ as Equation (7)

$(R(\lambda x y))=\frac{S(\lambda x y)-D \lambda}{W(\lambda x y)-D \lambda}$

The average relative reflectance spectrum for each sample was then calculated automatically.

Each sampling batch was subjected to both Vis/NIR spectral data acquisition and determination of moisture ratio, shrinkage, change in CIELab colour, and rehydration ratio.

\subsubsection{Multivariate data analysis}

All data sets were imported into JMP software to perform PLS analysis on all batches at the same time by taking all quantitative factors (i.e. 2, 3 and $4 \mathrm{~mm}$ thickness; $60^{\circ} \mathrm{C}$ and $70{ }^{\circ} \mathrm{C}$ drying temperature; cv. Elstar and Golden delicious) into account, in order to obtain models robust to the variance. Pre-processing using mean centering and autoscaling was applied on variables before modelling approach. Mean centering is the standard basic steps in pre-processing of multivariate methods. It removes the mean spectra and moves the natural data origin to the multivariate mean. The average of each column is calculated and then subtracted from each value. Thus, the average of each mean centered column is zero. Autoscaling includes mean centering but after the column average subtraction, each value is divided by its respective column standard deviation. As a result, all the column has zero mean and unit variance [39]. First, principal component analysis (PCA) was performed on the entire spectral data (X-matrix) to identify the most important directions of variability in a multivariate data space. The same spectral dataset was used together with a block of quality 
values (moisture ratio, $\mathrm{L}^{*}, \mathrm{a}^{*}, \mathrm{~b}^{*}, \mathrm{BI}$, shrinkage and rehydration ratio) to build a predictive PLS regression model, so that these attributes can be predicted in the future directly from the measured spectra. Regression models were computed using the PLS regression through the nonlinear Iterative Partial Least Squares (NIPALS) algorithm and by testing a number of factors equal to 15 . The frequency distribution of variables was observed with the help of histogram and to define an appropriate experimental space, the data was summed over the intensities in the bins. Bins were chosen with a fixed width, or with a width that increases with almost equal distribution of the dataset. Each model was optimized by computing a binning with 10 data splits. The binning procedure decouples the linear order between the original quantitative values and allows any pattern in the relation between responses (X) and Y to be modelled [40]. The regression models were calculated by using the two-way cross-validation method which was adapted to overcome the dependency between the predicted error for new individuals and the optimization of the model parameter. The datasets were split into two groups: 1 . training and validation set and 2 . test set. The data were selected randomly and divided into $60 \%$ training set; $40 \%$ as the validation set. A set of independent data was set aside to test the model performance. Firstly, single cross validation was performed using the training and validation set which results in the model by using an optimal number of PLS components. The optimal number of latent variables (LV) or factors for PLS regression model were selected at the minimum predicted residual error sum of square (PRESS) of the validation set [41]. PRESS is defined as the sum of squares of deviation between predicted and reference values of quality parameters and was calculated using Equation (8)

PRESS $=\sum\left(\mathrm{y}_{\text {cal }}-\mathrm{y}_{\text {act }}\right)^{2}$

Thus, this model provides the predicted formula that is applied on test datasets (that is; statistically almost identical, including an independent test set consisting of the observations which were not included in the training and validation step). The calibration model was then used to predict an independent test dataset.

Model accuracy was evaluated using two parameters; adjusted coefficient of determination (adj $\mathrm{R}^{2}$ ) and root mean square error (RMSE) for training set (adj $\mathrm{R}_{\mathrm{T}}^{2}$ and $\mathrm{RMSE}_{\mathrm{T}}$ ) and cross-validation set $\left(\mathrm{R}_{\mathrm{V}}^{2}\right.$ and $\mathrm{RMSE}_{\mathrm{V}}$ ) The $\mathrm{R}^{2}$ and RMSE were defined in Eqs. (8), (9), and (10), respectively [42].

$\mathrm{R}^{2}=1-\frac{\sum\left(\mathrm{y}_{\mathrm{cal}}-\mathrm{y}_{\mathrm{act}}\right)^{2}}{\sum\left(\mathrm{y}_{\mathrm{cal}}-\mathrm{y}_{\text {mean }}\right)^{2}}$

$\operatorname{RMSE}_{\mathrm{V}}=\sqrt{\sum \frac{\left(\mathrm{y}_{\mathrm{cal}}-\mathrm{y}_{\mathrm{act}}\right)^{2}}{\mathrm{n}}}$

$\operatorname{RMSE}_{\mathrm{p}}=\sqrt{\sum \frac{\left(\mathrm{y}_{\text {pred }}-\mathrm{y}_{\mathrm{act}}\right)^{2}}{\mathrm{n}}}$

where $\mathrm{n}$ is the number of spectra (samples), $\mathrm{y}_{\text {act }}$ is the actual value, $\mathrm{y}_{\text {mean }}$ is mean value, $\mathrm{y}_{\text {cal }}$ is the calculated value from calibration model, $\mathrm{y}_{\text {pred }}$ is the predicted value of the MR, $\mathrm{L}^{*}, \mathrm{a}^{*}, \mathrm{~b}^{*}$ and BI in apple slices samples estimated by validation method.

The standard outputs such as adj. ${ }^{2}$, RMSE for the training, validation and testing datasets were used to evaluate the model quality and to assess the influences of predictors. High adjusted $\mathrm{R}^{2}$ and low RMSE values indicate the best model for predicting the quality parameters.

Additionally, the variable importance in the projection (VIP) was used to select the important wavelength regions from the PLS models [43]. The VIP scores obtained by PLS regression can be used to select the most influential variables or predictors, $\mathrm{X}$. The VIP score can be estimated for jth X-variable by Eq. (11).

$\mathrm{V}_{\mathrm{j}=\sqrt{\mathrm{P}}} \sum_{\mathrm{a}=1}^{\mathrm{A}} \mathrm{SS}_{\mathrm{a}} \frac{\left(\frac{\mathrm{W}_{\mathrm{aj}}}{\mathrm{W}_{\mathrm{a}}}\right)^{2}}{\mathrm{SST}}$ where $\mathrm{P}$ is the total number of variables, $\mathrm{A}$ is the total number of components, $\mathrm{SS}_{\mathrm{a}}$ is the sum of squares explained by the $\mathrm{a}^{\text {th }}$ component, SST is the total variance explained by all the components, $\left(\frac{W_{a j}}{W_{a}}\right)^{2}$ is calculated using loading weight vectors $\mathrm{W}_{\mathrm{aj}}$ for each component and represents the importance of the variable $\mathrm{j}$ for component $\mathrm{a}$. The predictor variable whose VIP score is greater than 0.8 is considered as an important variable in this study considering the average of squared VIP score [44].

The Bland Altman method of differences [45] was used to assess the agreement of routine laboratory methods (destructive) and hyperspectral imaging approach (non-destructive) in determining the MR, colour parameter CIELab, BI, shrinkage and RR of the apple slices. The Bland Altman method is expressed with the $95 \%$ limits of agreement that is estimated by mean difference \pm 1.96 standard deviations and these values define the range within which most differences between measurements by the two methods would occur. Thus, the smaller the range between these two limits the better the agreement between the measurements [46].

Furthermore, regression analyses are determined by using the equation of the fitting line. The basic principle is that the fitting line has a slope of 1 , an intercept of 0 and the data points scatter very closely around the regression line. However, an empirical result can deviate from the ideal result in various ways. Thus, the bias of the test method can be calculated by the difference between the regression line (fitting line) and the line of equality $(y=x)$. The Passing Bablok linear regression analysis technique was also used to estimate the agreement of analytical methods agreement and to detect possible systematic bias between measurement methods. It is a non-parametric statistical test procedure [47]. Orthogonal (Deming) Regression was also determined which present both $\mathrm{x}$ and $\mathrm{y}$ random error that are proportional to the overall average value of the test and comparative results for each sample [48].

\subsection{Statistical analysis}

The effects of drying temperature, apple variety, slice thickness and their mutual interactions on Change in CIELab parameters, and $\Delta \mathrm{BI}$ were examined by using Analysis of Variance. 95\% confidence level was considered as the critical P-value to determine the effect of the parameters on the CIELab colour parameters.

Matlab software R2015b coupled with the 'Image Processing' toolbox was used to process the hypercube of apple samples and to acquire the relative area shrinkage of each slice.

All computations and multivariate data analyses were performed with the JMP software (SAS Institute Inc., Cary, NC, USA) and hypercube image processing were done using Matlab 2015a (The Mathworks Inc., Natick, MR, USA).

\section{Results and discussion}

\subsection{Drying behaviour (Effect of variables on drying time)}

Fig. 3 shows the drying curves for two apple varieties (Elstar and Golden Delicious) considering three thickness (2, 3 and $4 \mathrm{~mm}$ ) based on the moisture ratio values at $60{ }^{\circ} \mathrm{C}$ and $70{ }^{\circ} \mathrm{C}$ drying temperatures.

It has been observed that the drying time to reach the final moisture content of $12 \%$ were 123, 243 and $248 \mathrm{~min}$ for Elstar and 244, 260, $288 \mathrm{~min}$ for Golden Delicious for the slice thicknesses of 2, 3 and $4 \mathrm{~mm}$ respectively, at the drying air temperature of $60{ }^{\circ} \mathrm{C}$. Corresponding values for Elstar variety of 2, 3 and $4 \mathrm{~mm}$ slice thicknesses were 62, 118 and $174 \mathrm{~min}$ and 59, 103 and $119 \mathrm{~min}$ for Golden Delicious at the drying temperature of $70{ }^{\circ} \mathrm{C}$. As expected and already showed by previous studies $[10,49,50]$, the higher the drying temperature and thinner the slice, shorter the drying time to achieve the same final moisture content. In this study, the reduction of apple slices from $3 \mathrm{~mm}$ to $2 \mathrm{~mm}$ 
(a)

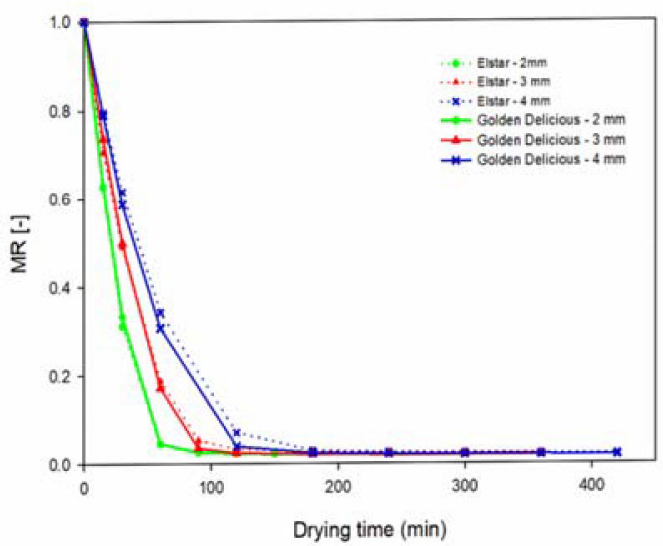

(b)

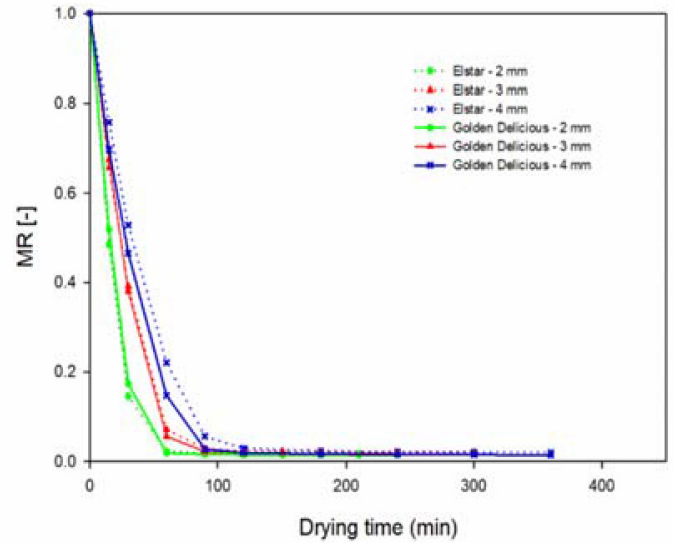

Fig. 3. $2 \mathrm{~mm}, 3 \mathrm{~mm}$, and $4 \mathrm{~mm}$ thickness apple slices (cv. Elstar and Golden Delicious) drying process at $60{ }^{\circ} \mathrm{C}$ (a) and $70{ }^{\circ} \mathrm{C}$ (b).

resulted in a decreased drying time of ca. $50 \%$ which is in agreement with the study done by Sturm, [32]. However, reduction of apple slices from $4 \mathrm{~mm}$ to $3 \mathrm{~mm}$ resulted in a non-uniform decrease for drying time of both varieties at both drying temperatures. This might be due to inhomogeneous structure of apple slices and initial moisture content.

\subsection{Colour assessment}

It is well known from literature that particle dimensions (slice thickness) and process settings (temperature) impact on colour changes during the drying process [10,51-53]. In this study slice thickness, apple variety and drying temperature show the greatest influence on the colour parameters (Table 1).

For Elstar the $\Delta \mathrm{L}^{*}$ values were not significantly different for for all drying parameter settings. It was observed that the $\Delta \mathrm{L}^{*}$ values of $3 \mathrm{~mm}$ slices dried at $70{ }^{\circ} \mathrm{C}$ of Golden Delicious variety were higher and significantly different compared to the slices of 3 and $4 \mathrm{~mm}$ dried at $60^{\circ} \mathrm{C}$ and $2 \mathrm{~mm}$ at $70^{\circ} \mathrm{C}$. In terms of the reduction in redness of the slices, $2 \mathrm{~mm}$ slice of Elstar dried at $60^{\circ} \mathrm{C}$ and $70^{\circ} \mathrm{C}$ showed a significantly lower redness compared to $4 \mathrm{~mm}$ slices dried at $60^{\circ} \mathrm{C}$ and $70{ }^{\circ} \mathrm{C}$ but were not significantly different to $3 \mathrm{~mm}$ slices dried at both temperatures. In case of Golden Delicious, $2 \mathrm{~mm}$ slices dried at $70^{\circ} \mathrm{C}$ had a lower redness compared to $4 \mathrm{~mm}-60^{\circ} \mathrm{C}, 3 \mathrm{~mm}-70^{\circ} \mathrm{C}$ and $4 \mathrm{~mm}-$ $70^{\circ} \mathrm{C}$ slices. It can be observed that the magnitude of the change in $\mathrm{b}^{*}$ were higher in $4 \mathrm{~mm}-60^{\circ} \mathrm{C}$ Elstar slices which was significantly different to $4 \mathrm{~mm}-70^{\circ} \mathrm{C}$ slices. Similarly, in Golden Delicious, $4 \mathrm{~mm}-$ $60^{\circ} \mathrm{C}$ slices reached higher values which was only significantly different to $2 \mathrm{~mm}$ dried at $60{ }^{\circ} \mathrm{C}$.

Table 1

CIELab and BI parameter of apple slices at different settings.

\begin{tabular}{llllll}
\hline Variety & Level & $\Delta \mathrm{L} *$ & $\Delta \mathrm{a} *$ & $\Delta \mathrm{b} *$ & $\Delta \mathrm{BI}$ \\
\hline \multirow{2}{*}{ Elstar } & $2 \mathrm{~mm}-60^{\circ} \mathrm{C}$ & $-0.15 \mathrm{a}$ & $1.61 \mathrm{~b}$ & $12.32 \mathrm{ab}$ & $2.26 \mathrm{~b}$ \\
& $3 \mathrm{~mm}-60^{\circ} \mathrm{C}$ & $-6.06 \mathrm{a}$ & $3.65 \mathrm{ab}$ & $12.46 \mathrm{ab}$ & $5.62 \mathrm{~b}$ \\
& $4 \mathrm{~mm}-60^{\circ} \mathrm{C}$ & $-4.38 \mathrm{a}$ & $5.36 \mathrm{a}$ & $16.64 \mathrm{a}$ & $10.12 \mathrm{a}$ \\
& $2 \mathrm{~mm}-70^{\circ} \mathrm{C}$ & $-9.49 \mathrm{a}$ & $2.79 \mathrm{~b}$ & $10.92 \mathrm{ab}$ & $4.61 \mathrm{~b}$ \\
& $3 \mathrm{~mm}-70^{\circ} \mathrm{C}$ & $-4.88 \mathrm{a}$ & $3.30 \mathrm{ab}$ & $13.29 \mathrm{ab}$ & $5.08 \mathrm{~b}$ \\
Golden delicious & $4 \mathrm{~mm}-70^{\circ} \mathrm{C}$ & $-7.93 \mathrm{a}$ & $5.35 \mathrm{a}$ & $10.35 \mathrm{~b}$ & $7.17 \mathrm{ab}$ \\
& $2 \mathrm{~mm}-60^{\circ} \mathrm{C}$ & $-9.89 \mathrm{ab}$ & $4.15 \mathrm{bc}$ & $9.54 \mathrm{~b}$ & $7.08 \mathrm{bc}$ \\
& $3 \mathrm{~mm}-60^{\circ} \mathrm{C}$ & $-5.68 \mathrm{a}$ & $5.49 \mathrm{abc}$ & $17.76 \mathrm{ab}$ & $8.09 \mathrm{abc}$ \\
& $4 \mathrm{~mm}-60^{\circ} \mathrm{C}$ & $-6.52 \mathrm{a}$ & $7.35 \mathrm{ab}$ & $19.93 \mathrm{a}$ & $10.39 \mathrm{ab}$ \\
& $2 \mathrm{~mm}-70^{\circ} \mathrm{C}$ & $-6.62 \mathrm{a}$ & $3.43 \mathrm{c}$ & $14.68 \mathrm{ab}$ & $5.65 \mathrm{c}$ \\
& $3 \mathrm{~mm}-70^{\circ} \mathrm{C}$ & $-12.05 \mathrm{~b}$ & $8.12 \mathrm{a}$ & $18.31 \mathrm{a}$ & $11.78 \mathrm{a}$ \\
& $4 \mathrm{~mm}-70^{\circ} \mathrm{C}$ & $-10.01 \mathrm{ab}$ & $7.91 \mathrm{a}$ & $16.25 \mathrm{ab}$ & $10.82 \mathrm{ab}$
\end{tabular}

Levels not connected by same letter are significantly different.
With regards to $\Delta \mathrm{BI}, 4 \mathrm{~mm}$ Elstar slices dried at $60^{\circ} \mathrm{C}$ showed more pronounced browing compared to $2,3 \mathrm{~mm}$ dried at $60^{\circ} \mathrm{C}$ and $70^{\circ} \mathrm{C}$ but was not significantly different to $4 \mathrm{~mm}$ slice dried at $70^{\circ} \mathrm{C}$. This indicates that due to the higher volume to surface area, the product stays in a higher moist state for a longer period of time, which in consequence leads to a darker finished product $[54,55]$. Moreover, this could be attributed to the chemical, biochemical and physical changes which occur during drying which lead to quality changes such as a change in colour [32]. For Golden delicious, it was observed that $3 \mathrm{~mm}$ slice dried at $70^{\circ} \mathrm{C}$ showed the highest $\Delta \mathrm{BI}$ which is only significantly different to $2 \mathrm{~mm}$ slices dried at $60^{\circ} \mathrm{C}$ and $70^{\circ} \mathrm{C}$ drying temperature. Furthermore, for all settings, the degree of browning for Golden delicious was higher than for Elstar. This might be due to the presence of a higher concentration of phenolic compounds in Golden delicious which accelerates the development of the brown colour [56]. Additionally, it might be due to high levels of non-enzymatic browning or Maillard reaction and oxidation of ascorbic acid [5,57]. Therefore, with an increase in the thickness of apple slices $(4 \mathrm{~mm})$, the development of brown colour increases consecutively in both apple varieties dried at $60{ }^{\circ} \mathrm{C}$ and $70^{\circ} \mathrm{C}$ as the heat exposure increases to remove the moisture content [58,59].

\subsection{PLS analysis}

\subsubsection{Selection of wavebands from VIP plot}

Fully cross-validated PLS regression models were developed for MR, $L^{*}, a^{*}, b^{*}, B I, S$, and RR to predict each quality attribute. The optimum number of latent factors was used to build a robust PLS regression model to obtain the best prediction performance. The optimum number of PLS-latent variables for each feature and the number of factors that produced the least PRESS was selected as optimum value. Fig. 4 shows a typical plot of PRESS for each analyte as a function of the number of factors. As seen, the PRESS for MR (a), L*(b), a* (c), b*(d), BI (e), S (f) and $R R(g)$ reaches to a minimum a latent variable equal to $13,7,14,7$, 13, 15 and 6 respectively. The minimum root mean PRESS for MR, $L^{*}$, $a^{*}, b^{*}$ and BI were $0.27,0.63,0.36,0.37,0.26,0.17$ and 0.57 respectively. These factors were selected to avoid overfitting (which occurs by selecting too many latent variables, poor splitting of training and testing data sets) and under fitting (selecting fewer variables). Thus, these optimum factors were good enough to capture, and model the variability in the data. PLS regression was applied across all spectral data using the respective latent factors for the simultaneous determination of the analytes using the validation method.

Fig. 5 shows the Variable Importance Plot (VIP) scores of the 329 wavelengths (491-1005 nm) X-variables for MR (a), L* (b), a* (c), b* 

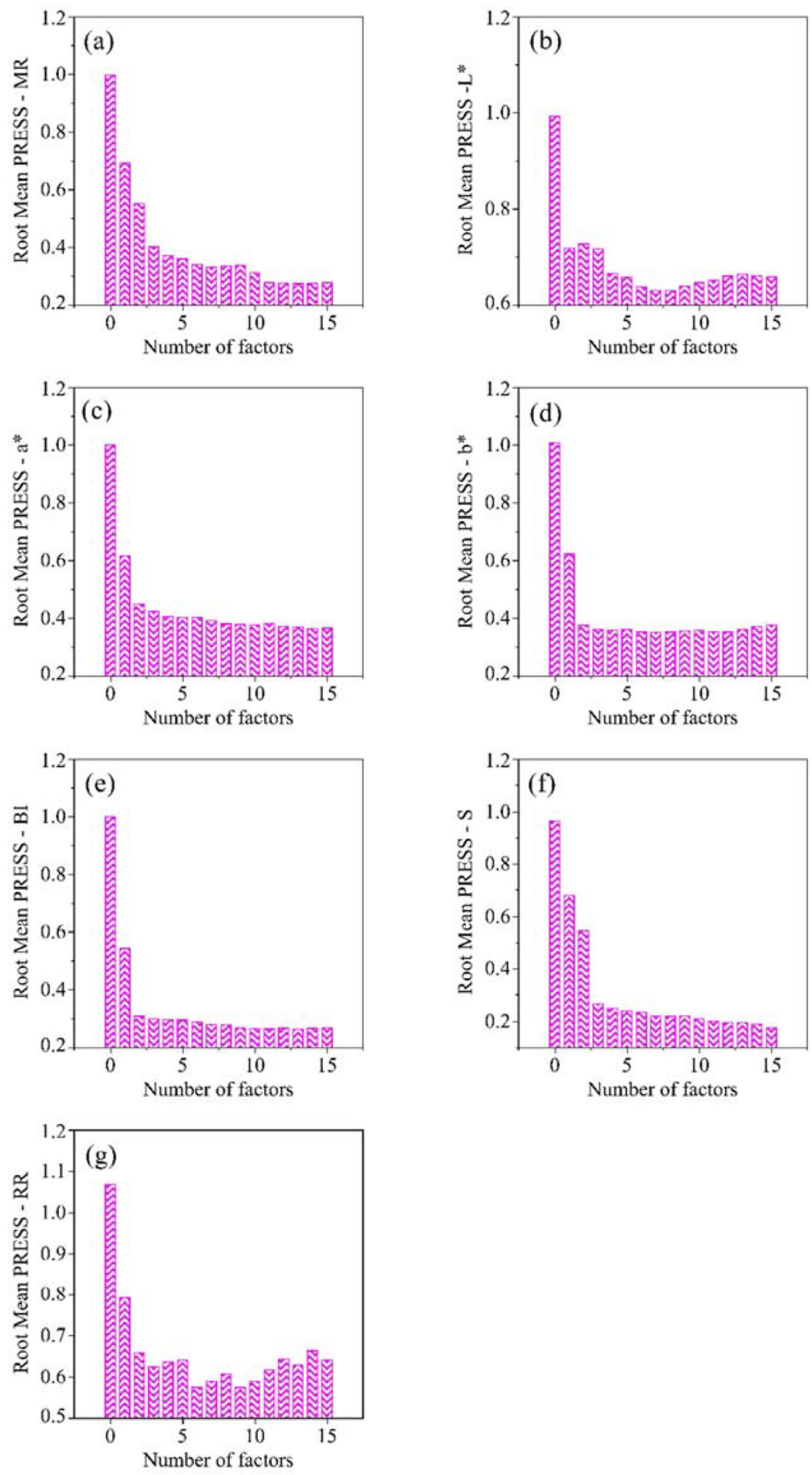

Fig. 4. RMSE PRESS plot for MR (a), $L^{*}(b), a^{*}(c), b^{*}(d), B I(e), S(f)$ and RR (g) as a function of number of factors. 

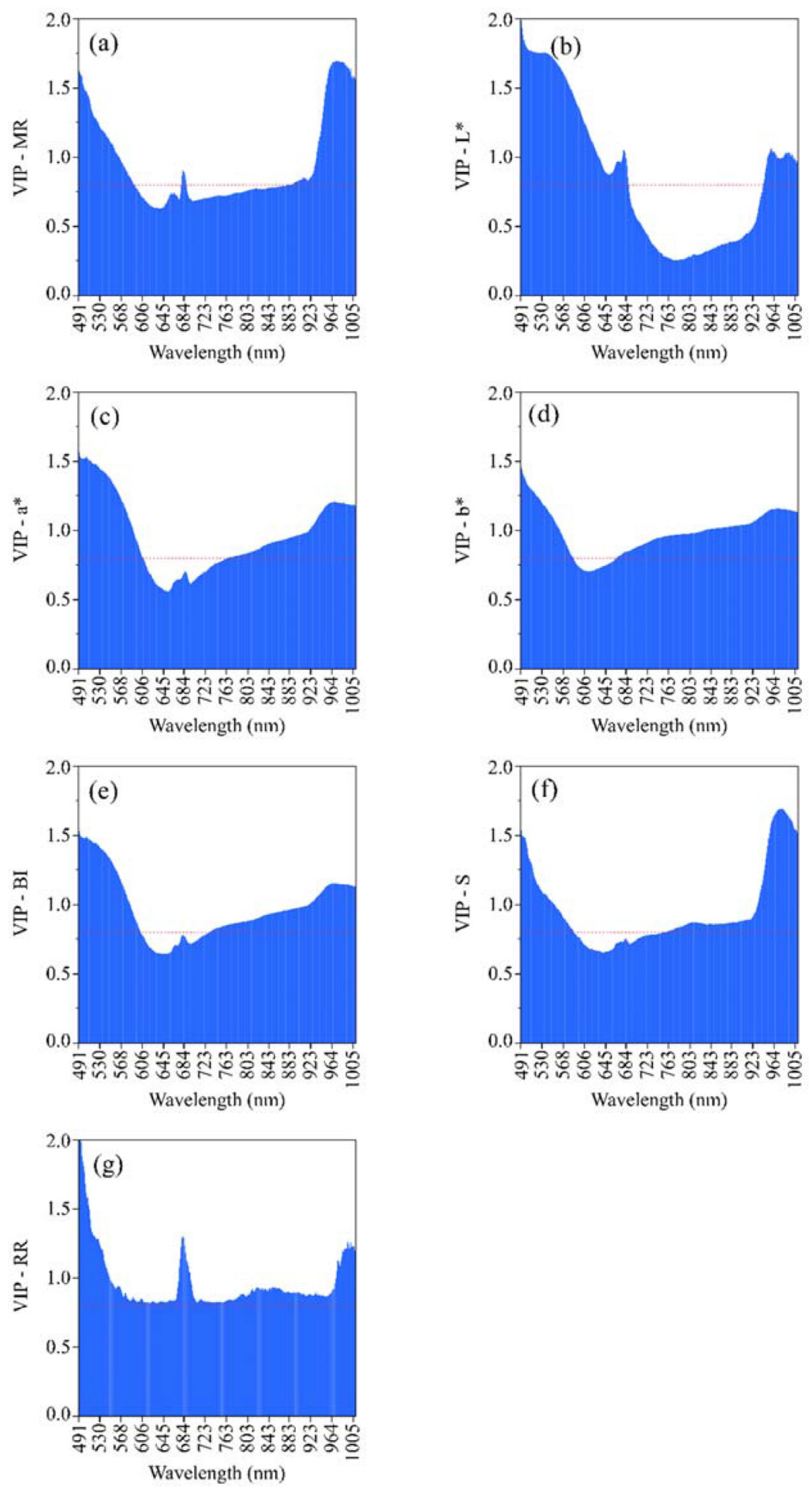

Fig. 5. VIP plot for MR (a), $L^{*}(b), a^{*}(c), b^{*}(d), B I(e), S(f)$ and RR (g) as a function of wavelength. 

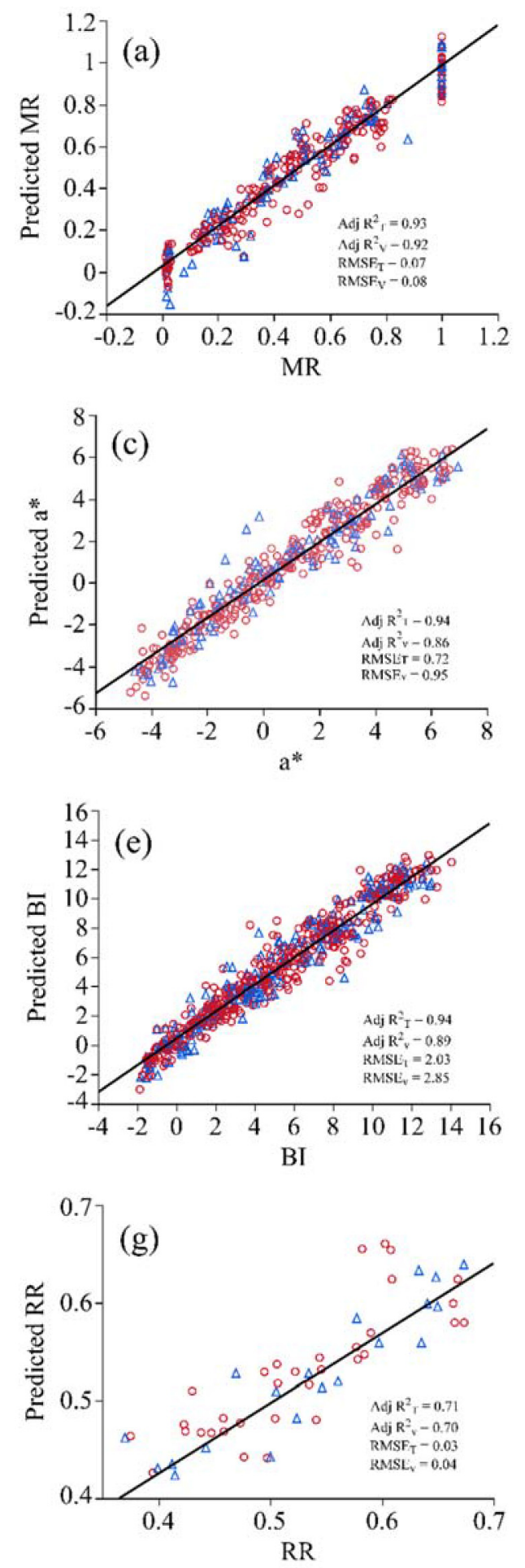
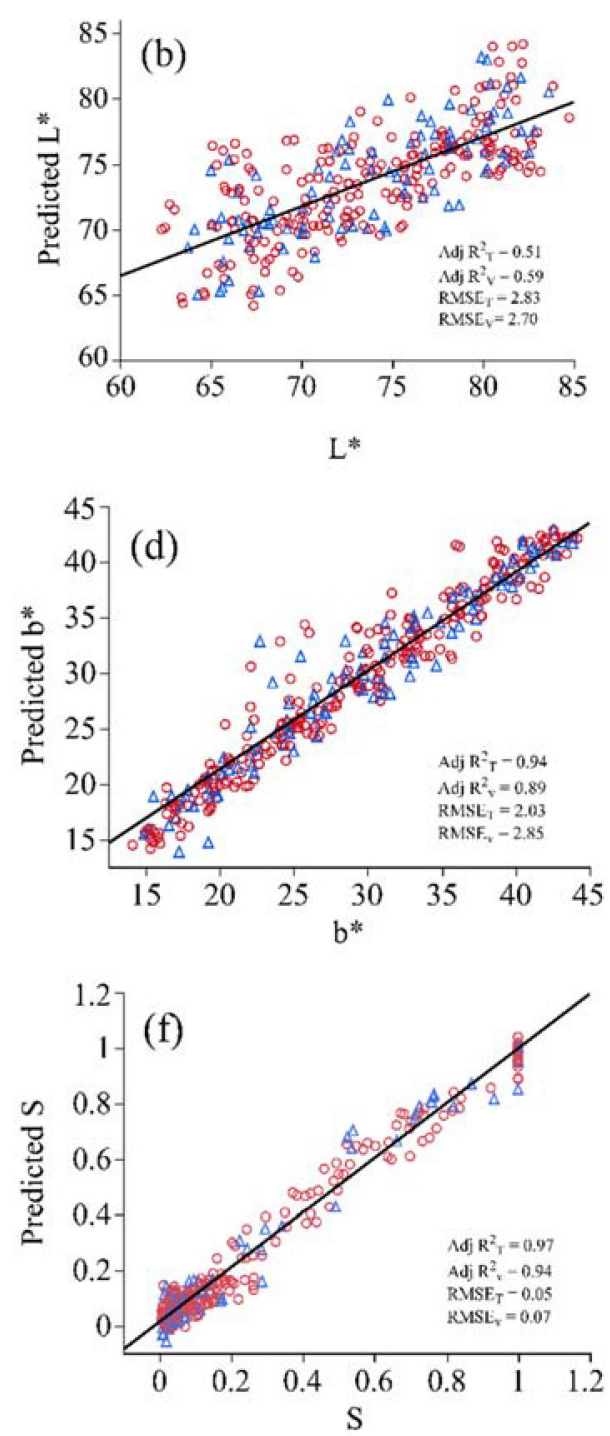

Fig. 6. Partial least squares models for MR (a), L* (b), a* (c), b* (d), BI (e), S (f) and RR (g) using training (blue) and validation (red) set of apple samples.

(d) and BI (e). In this study, X-variables (spectral wavelengths) with a VIP score greater than 0.8 are considered as important variables for the modelling of the metric (Y-variables) to be modelled. However, VIP cutoff points vary throughout the literature $[60,61]$. Clearly, MR and L* parameter have VIP scores greater than 0.8 which might be related to the part that connects to the water distribution at $970 \mathrm{~nm}$ and change in pigments at $685 \mathrm{~nm}$. The wavelengths at $970 \mathrm{~nm}$ and $685 \mathrm{~nm}$ are significant parameters in describing the water content distribution and chlorophyll content in apple slices which aligns well with the several studies $[39,62,63]$.

\subsubsection{PLS regression modeling}

PLS models were developed using data from all apple slices, regardless of apple variety, slice thickness, drying times and drying temperatures to maximize the predictability of Vis/NIR hyperspectral imaging from a wide range of reference values and to make a real world application more feasible. The measured values obtained from the routine laboratory test (destructive) for the different quality attributes and predicted values for these same samples resulting from the optimal PLSR models are plotted and displayed in Fig. 6. The PLS models for $\mathrm{MR}, \mathrm{a}^{*}, \mathrm{~b}^{*}, \mathrm{BI}$, and shrinkage gave a very good statistical performance 

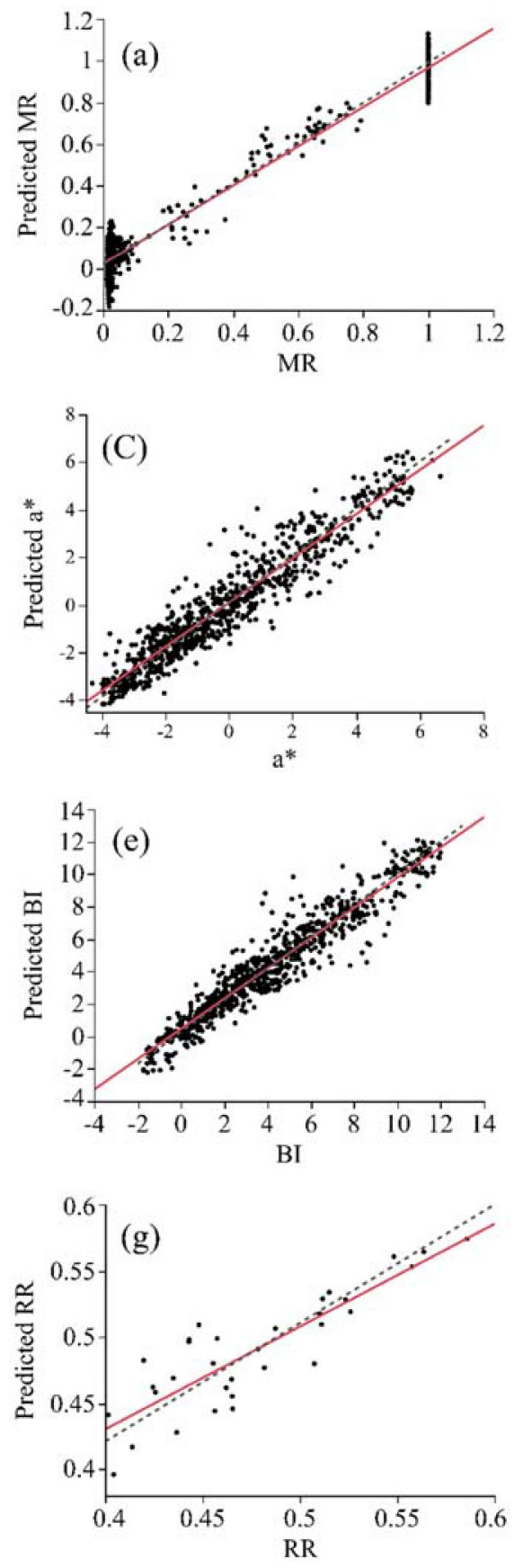

which is shown by high adj $R^{2}$ and low RMSE. The adjusted $R^{2}$ for MR is 93\% with an RMSE of 0.32 , a* (adj of 86\%, RMSE of 0.95), b* (89\% adj $\mathrm{R}^{2}$ and $2.82 \mathrm{RMSE}$ ) and $\mathrm{BI}$ (93\% adj $\mathrm{R}^{2}$ and $\left.1.10 \mathrm{RMSE}\right)$. This indicates very good prediction ability of the resulting models with the reproduction of calibration data. However, the prediction of color component $\left(\mathrm{L}^{*}\right)$ was not satisfactory which might be attributed to the narrow range $(70.63-78.93)$ of $L^{*}$ values involved in building its PLS regression calibration model. The significantly higher changes in $\mathrm{L}^{*}$ for the hyperspectral images could be caused by glossiness or the increasing unevenness of the product surface during the drying process [7]. Additionally, there might be pigment transfer during the drying process. Nevertheless, it is notable that VIP score shows the range of wavelengths for $L^{*}$ parameter but its performance is not as good as to be used for quantification of $\mathrm{L}^{*}$ prediction. The prediction performance for rehydration ratio was good with $70 \%$ adj $\mathrm{R}^{2}$ and 0.040 RMSE. The PLS regression models using the Vis/NIR spectra appeared to be robust
Fig. 7. Prediction of the variables [MR (a), $\left.L^{*}(b), a^{*}(c), b *(d), B I(e), S(f), R R(g)\right]$ using the PLS validation model of independent samples. The dotted line represents the line of best fit while the red line is a reference line plotted at the diagonal. Bland Altman plot showing the difference against the average of test hyperspectral imaging method and standard measurements with limits of agreement (LoA) (broken lines) for the variables [MR (h), L* (i), a*(j), b*(k), BI (l), S (m), RR (n)]. X-axis represents the mean of the two variables and the $\mathrm{Y}$-axis depicts the difference. The solid red line represents the mean and the dotted lines show the standard deviation. When the plot shows no relationship between discrepancy and the level of measurement, so that LoA are valid.

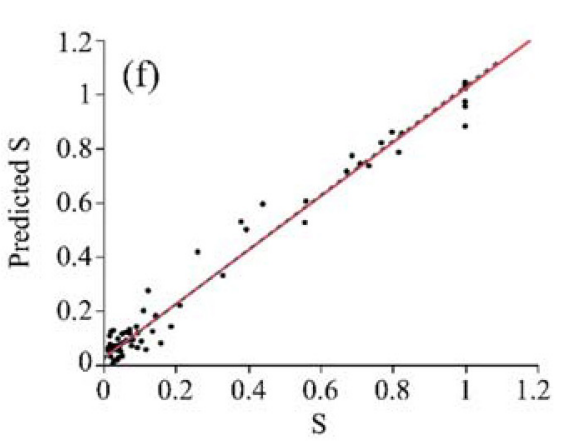


Table 2

Regression data from method comparison for MR, $L^{*}, a^{*}, b^{*}, B I$ measured by hyperspectral imaging as a reference method $(x)$ and routine laboratory measurement $(\mathrm{Y})$.

\begin{tabular}{|c|c|c|c|c|c|c|}
\hline \multirow[t]{2}{*}{ Variable } & \multirow[t]{2}{*}{ Variance fit ratio } & \multirow[t]{2}{*}{$\mathrm{r}$} & \multicolumn{2}{|c|}{ Slope } & \multicolumn{2}{|c|}{ Intercept } \\
\hline & & & DR & PBR & DR & PBR \\
\hline MR & 0.96 & 0.95 & 0.98 & 7.5 & 0.02 & -0.14 \\
\hline$L^{*}$ & 0.94 & 0.66 & 0.97 & 0.96 & 1.85 & 1.98 \\
\hline$a^{*}$ & 0.94 & 0.94 & 0.97 & 0.98 & 0.09 & 0.03 \\
\hline$b^{*}$ & 0.96 & 0.94 & 0.98 & 0.97 & 0.60 & 0.54 \\
\hline BI & 0.96 & 0.95 & 0.98 & 0.95 & 0.60 & 0.50 \\
\hline $\mathrm{RR}$ & 1.20 & 0.86 & 1.09 & 1.08 & -0.06 & -0.05 \\
\hline Shrinkage & 0.98 & 0.98 & 0.99 & 0.96 & -0.02 & -0.01 \\
\hline
\end{tabular}

$\mathrm{r}$ - indicates the correlation coefficient; DR indicates the Deming's regression; PBR indicates the Passing Bablok regression.

predicting $\mathrm{L}^{*}$ colour parameter and rehydration ratio appeared to be not as good since the adjusted correlation of determination coefficients was low. This could be elucidated to the differences in absorbance patterns due to structural changes in the slices for different apple variety and thickness. Additionally, the analysis was performed on a large number of samples which might be heterogeneous and wide variation in apple slices [64] resulting in low prediction performance. Therefore, the accuracy of the regression model is evaluated as being excellent for the prediction of MR, a*, b*, BI and shrinkage detection in this study.

Fig. 7 (h, i, j, k, 1, m, n) shows Bland Altman plots which are used to compare the agreement between the laboratory measurement (destructive) system and non-destructive analysis system for MR, L*, a*, $b^{*}, \mathrm{BI}, \mathrm{S}$, and RR parameters. Since there is no relationship between difference and average of data from the conventional approach and non-destructive method, the limit of agreement between these methods using difference and average were used. The results are presented as the differences between the two methods that lie between the limit of agreements (mean \pm 1.96 standard deviations). As seen in Fig. 4b, the mean of differences for MR was 0.017 with a standard deviation of 0.003 , and the limit of agreement [95\% confidence interval (CI)] was reported as $0.011-0.024$. The mean of differences for $L^{*}$ and predicted $L^{*}$ was observed as -0.39 with a standard deviation of 0.111 . The limit of agreement was observed as -0.609 : -0.172 . Similarly, the mean of differences for $\mathrm{a}^{*}, \mathrm{~b} *$ and BI was found as $0.095,-0.079,0.171$ with a standard deviation and limit of agreement value of 0.875 (1.81: $-1.62), 2.33$ (4.49: -4.65$)$ and $1.04(2.22:-1.88)$ respectively.

These results suggested that the data points for MR, $\mathrm{L}^{*}, \mathrm{a}^{*}, \mathrm{~b}^{*}$ and $\mathrm{BI}$ were within the limits of agreement (with nearly equal distribution of over and underestimation of respective values). The results in this study agreed with the statistical limits [65], which are calculated by using the mean and the standard deviation of the differences between the predicted formula and measure responses. Furthermore, the standard deviation of the difference between HSI and the laboratory (destructive) measurements was relevantly small showing an acceptable precision and both methods can be interchangeable to predict the moisture ratio and colour components CIE $\mathrm{L}^{*} \mathrm{a}^{*} \mathrm{~b}^{*}$. Thus, it was possible to assess two independent methods of measuring the same variable, each of which might have its own inherent error. However, some large differences were seen when measuring the $L^{*}$ parameter, shrinkage and rehydration ratio. Therefore, a poor agreement exists between the destructive approach and hyperspectral imaging in the measurement of $\mathrm{L}^{*}$, shrinkage and rehydration ratio.

In the Deming regression analysis, a slope of 0.98 (95\% CI $[0.96$ to1.00]), the intercept of 0.02 and variance fit ratio of 0.96 was observed for MR, showed both destructive and hyperspectral imaging measurement methods have a good concordance. The concordance correlation coefficient was 0.95 , which is considered as acceptable performance between two measurements to determine MR in apple slices. Similarly, for $\mathrm{L}^{*}, \mathrm{a}^{*}, \mathrm{~b}$ * and BI value have a slope of 0.97 (95\% CI [0.98 to1.04]), 0.99 (95\% CI [0.96 to1.01]), 0.98 (95\% CI [0.95 to1.005]) and 0.98 (95\% CI [0.95 to1.005]) respectively. The intercept for $\mathrm{L}^{*}$ was 1.85 , b* was 0.09 , a* was 0.602 and $\mathrm{BI}$ was 0.60 . The variance fit ratio for $\mathrm{L}^{*}, \mathrm{a}^{*}, \mathrm{~b}^{*}$ and BI was observed as 0.94, 0.98, 0.96, 0.96 respectively. Additionally, the Passing and Bablok regression analysis showed a close agreement of both slope and intercept, with the target values of 1 and 0 within the $95 \%$ confidence except for MR value as presented in Table 2 .

\section{Conclusions}

Prediction models based on the Vis/NIR spectrum can be very useful to rapidly, cheaply and easily predict the quality parameters of apple slices of the different apple varieties such as moisture ratio, CIELab chromaticity, and shrinkage and rehydration ratio. The Vis/NIR based prediction models have shown to be reliable for the moisture ratio, a*, $\mathrm{b}^{*}$, browning index, rehydration ratio and shrinkage prediction of apple slices irrespective of the apple varieties, apple slice thickness, drying temperatures and drying time. Since the differences between the routine laboratory method and non-invasive hyperspectral imaging measurements were small, hyperspectral imaging technique could replace measurement in a laboratory during the drying process or the two methods could be used interchangeably.

Such models showed robustness that could be further used for quality optimization in different apple varieties during the on-line drying process. Only the accuracy of the $L^{*}$ and RR parameters should be improved to enhance further the $L^{*}$ and RR prediction models. However, it was found that all the devices showed satisfactory precision, but there was substantial disagreement when their results were compared to a laboratory reference. Therefore, HSI can be used for the development of smart drying systems as real-time measurement of product characteristics becomes possible. Further research is needed in this work that consider more samples with different species and growing regions to improve the robustness of the model. Additionally, the visualization of chemical components distribution such as phenolic content in apple using the Vis/NIR HSI technology will also be a point of future interest investigation.

\section{Acknowledgement}

The authors would like to acknowledge the Katholischer Akademischer Ausländer Dienst (KAAD) Germany for providing a $\mathrm{PhD}$ stipendium to the first author. The authors also wish to express their appreciation to the Core Organic Plus Programme for the financial support within the SusOrgPlus project (project number BLE-170E005). The authors also wish to thank Ms Sharvari Raut for her immense support and help.

\section{References}

[1] WHO, Increasing fruit and vegetable consumption to reduce the risk of noncommunicable diseases [WWW Document]. WHO. URL https://www.who.int/ elena/titles/fruit_vegetables_ncds/en/ (accessed 6.12.19), 2019.

[2] L.M. Diamante, Y. Yamaguchi, Response surface methodology for optimisation of hot air drying of blackcurrant concentrate infused apple cubes, Int. Food Res. J. 19 (2012) 353-362.

[3] X. Wang, C. Li, D. Liang, Y. Zou, P. Li, F. Ma, Phenolic compounds and antioxidant activity in red-fleshed apples, J. Funct. Foods 18 (2014) 1-9, https://doi.org/10. 1016/j.jff.2014.06.013.

[4] B. Arora, S. Sethi, A. Joshi, V.R. Sagar, R.R. Sharma, Antioxidant degradation kinetics in apples, J. Food Sci. Technol. 55 (2018) 1306-1313, https://doi.org/10. 1007/s13197-018-3041-1.

[5] A. Vega-Gálvez, K. Ah-Hen, M. Chacana, J. Vergara, J. Martínez-Monzó, P. GarcíaSegovia, R. Lemus-Mondaca, K. Di Scala, Effect of temperature and air velocity on drying kinetics, antioxidant capacity, total phenolic content, colour, texture and microstructure of apple (var. Granny Smith) slices, Food Chem. 132 (2012) 51-59, https://doi.org/10.1016/j.foodchem.2011.10.029.

[6] B. Ertekin Filiz, A.C. Seydim, Kinetic changes of antioxidant parameters, ascorbic acid loss, and hydroxymethyl furfural formation during apple chips production, J. 
Food Biochem. 1-10 (2018), https://doi.org/10.1111/jfbc.12676.

[7] B. Sturm, W.C. Hofacker, O. Hensel, Optimizing the Drying Parameters for Hot-AirDried Apples, Dry. Technol. 30 (2012) 1570-1582, https://doi.org/10.1080/ 07373937.2012.698439.

[8] R. Moscetti, F. Raponi, S. Ferri, A. Colantoni, D. Monarca, R. Massantini, Real-time monitoring of organic apple (var. Gala) during hot-air drying using near-infrared spectroscopy, J. Food Eng. 222 (2018) 139-150, https://doi.org/10.1016/j. jfoodeng.2017.11.023.

[9] A. Kaleta, K. Górnicki, Evaluation of drying models of apple (var. McIntosh) dried in a convective dryer, Int. J. Food Sci. Technol. 45 (2010) 891-898, https://doi.org/ 10.1111/j.1365-2621.2010.02230.x.

[10] B. Sturm, A.-M. Nunez Vega, W.C. Hofacker, Influence of process control strategies on drying kinetics, colour and shrinkage of air dried apples, Appl. Therm. Eng. 62 (2014) 455-460, https://doi.org/10.1016/j.applthermaleng.2013.09.056.

[11] J. Kschonsek, T. Wolfram, A. Stöckl, V. Böhm, Polyphenolic Compounds Analysis of Old and New Apple Cultivars and Contribution of Polyphenolic Profile to the In Vitro Antioxidant Capacity, Antioxidants 7 (2018) 20, https://doi.org/10.3390/ antiox7010020.

[12] N.O. Violeta, I. Trandafir, M.E. Ionica, Compositional characteristics of fruits of several apple (Malus domestica Borkh.) cultivars, Not. Bot. Horti Agrobot. ClujNapoca 38 (2010) 228-233, https://doi.org/10.15835/nbha3834762.

[13] M. Kalinowska, A. Bielawska, H. Lewandowska-Siwkiewicz, W. Priebe W. Lewandowski, Apples: content of phenolic compounds vs. variety, part of apple and cultivation model, extraction of phenolic compounds, biological properties, Plant Physiol. Biochem. 84 (2014) 169-188, https://doi.org/10.1016/j.plaphy. 2014.09.006.

[14] G. ElMasry, N. Wang, A. ElSayed, M. Ngadi, Hyperspectral imaging for nondestructive determination of some quality attributes for strawberry, J. Food Eng. 81 (2007) 98-107, https://doi.org/10.1016/j.jfoodeng.2006.10.016.

[15] S. Crichton, B. Sturm, A. Hurlbert, Moisture content measurement in dried apple produce through visible wavelength hyperspectral imaging Written for presentation at the 2015 ASABE Annual International Meeting Sponsored by ASABE New Orleans, Louisiana Hyperspectral Measurement Technique 7004 (2015).

[16] W. Amjad, S.O.J. Crichton, A. Munir, O. Hensel, B. Sturm, Hyperspectral imaging for the determination of potato slice moisture content and chromaticity during the convective hot air drying process, Biosyst. Eng. 166 (2018) 170-183, https://doi. org/10.1016/j.biosystemseng.2017.12.001.

[17] D.-W. Sun, A. Subramanian, L. Rodriguez-Saona, Infrared spectroscopy for foo quality analysis and control, Zhurnal Eksperimental'noi i Teoreticheskoi Fiziki (2009), https://doi.org/10.1016/B978-0-12-374136-3.00007-9.

[18] D. Liu, D.-W. Sun, J. Qu, X.-A. Zeng, H. Pu, J. Ma, Feasibility of using hyperspectral imaging to predict moisture content of porcine meat during salting process, Food Chem. 152 (2014) 197-204, https://doi.org/10.1016/j.foodchem.2013.11.107.

[19] L. Shrestha, R. Moscetti, S. Crichton, O. Hensel, B. Sturm, Organic apples (cv. Elstar) quality evaluation during hot-air drying using Vis/NIR hyperspectral imaging. IDS'2018 - 21st International Drying Symposium, 2018, pp. 11-14. https://doi.org/ 10.4995/ids2018.2018.7689.

[20] B. Sturm, Automatic control of apple drying with respect to product quality and air velocity, in: A. Martynenko, A.S. Mujumdar (Eds.), Intell. Control Dry, CRC Press Taylor \& Francis Group, 2019, pp. 212-226.

[21] A. Martynenko, Computer Vision for Real-Time Control in Drying, Food Eng. Rev. 9 (2017) 91-111, https://doi.org/10.1007/s12393-017-9159-5.

[22] A. Martynenko, B. Sturm, The shift of paradigm from steady-state to intelligent drying. 7th European Drying Conference, 2019.

[23] B. Sturm, Systemic optimisation and design approach for thermal food processes Increase of quality, process- and resource efficiency in dried agricultural products manufacturing, Habilitationsschrift, University of Kassel, Witzenhausen, 2017.

[24] H. El-Mesery, H. Mao, A. Abomohra, Applications of Non-destructive Technologies for Agricultural and Food Products Quality Inspection, Sensors 19 (2019) 846, https://doi.org/10.3390/s19040846.

[25] D. Wu, D.-W. Sun, Advanced applications of hyperspectral imaging technology for food quality and safety analysis and assessment: a review - Part I: Fundamentals, Innov. Food Sci. Emerg. Technol. 19 (2013) 1-14, https://doi.org/10.1016/j.ifset. 2013.04.016.

[26] A. Nawrocka, J. Lamorska, Determination of Food Quality by Using Spectroscopic Methods, INTECH Open Science Open Minds. (2013) 347-368, https://doi.org/10. $5772 / 52722$.

[27] Y. Lu, R. Lu, Quality Evalation of Apples, in: D.-W. (Ed.), Computer Vision Technology for Food Quality Evaluation. United States, 2016, p. 273.

[28] R.F. Martin, General deming regression for estimating systematic bias and its confidence interval in method-comparison studies, Clin. Chem. 46 (2000) 100-104.

[29] P. Sedgwick, Limits of agreement (Bland-Altman method), BMJ 346 (2013) 1-2, https://doi.org/10.1136/bmj.f1630.

[30] C.S. Hofman, R.J.F. Melis, A.R.T. Donders, Adapted Bland-Altman method was used to compare measurement methods with unequal observations per case, J. Clin. Epidemiol. 68 (2015) 939-943, https://doi.org/10.1016/j.jclinepi.2015.02.015.

[31] J. Ludbrook, Confidence in Altman-Bland plots: a critical review of the method of differences, Clin. Exp. Pharmacol. Physiol. 37 (2010) 143-149, https://doi.org/10. 1111/j.1440-1681.2009.05288.x.

[32] Sturm, B., SUS Organic Processing and Quality Guidelines for Organic Food Processing, 2018.

[33] M.U.H. Joardder, R.J. Brown, C. Kumar, M.A. Karim, Effect of cell wall properties on porosity and shrinkage of dried apple, Int. J. Food Prop. 18 (2015) 2327-2337, https://doi.org/10.1080/10942912.2014.980945.

[34] AOAC, Official methods of analysis 15thed, Association of Official Analytical Chemistry, Arlington, USA, 1990, p. 931.
[35] K. Rayaguru, W. Routray, Mathematical modeling of thin layer drying kinetics of stone apple slices, Int. Food Res. J. (2012) 19.

[36] S. Bußler, J. Ehlbeck, O.K. Schlüter, Pre-drying treatment of plant related tissues using plasma processed air: impact on enzyme activity and quality attributes of cut apple and potato, Innov. Food Sci. Emerg. Technol. 40 (2017) 78-86, https://doi. org/10.1016/j.ifset.2016.05.007.

[37] M. Maskan, Drying, shrinkage and rehydration characteristics of kiwifruits during hot air and microwave drying 48 (2001) 177-182.

[38] S. Crichton, L. Shrestha, A. Hurlbert, B. Sturm, Use of hyperspectral imaging for the prediction of moisture content and chromaticity of raw and pretreated apple slices during convection drying, Dry. Technol. 36 (2018), https://doi.org/10.1080/ 07373937.2017.1356847.

[39] Burger, James, E., Gowen, Aoife, A., Classification and Prediction Methods, in: B. Park, R. Lu (Eds.), Hyperspectral Imaging Technology in Food and Agriculture, 2015. pp. 305-329. https://doi.org/10.1007/978-1-4939-2836-1_13.

[40] A. Smolinska, L. Blanchet, L.M.C. Buydens, S.S. Wijmenga, NMR and pattern recognition methods in metabolomics: from data acquisition to biomarker discovery: a review, Anal. Chim. Acta 750 (2012) 82-97, https://doi.org/10.1016/j.aca.2012. 05.049.

[41] M.L. Sawatsky, M. Clyde, F. Meek, Partial least squares regression in the social sciences, Quant. Methods Psychol. 11 (2016) 52-62, https://doi.org/10.20982/ tqmp.11.2.p052.

[42] T. Chai, R.R. Draxler, C. Prediction, Root mean square error (RMSE) or mean absolute error (MAE)? - Arguments against avoiding RMSE in the literature (2014) 1247-1250. https://doi.org/10.5194/gmd-7-1247-2014.

[43] I.G. Chong, C.H. Jun, Performance of some variable selection methods when multicollinearity is present, Chemom. Intell. Lab. Syst. 78 (2005) 103-112, https://doi org/10.1016/j.chemolab.2004.12.011.

[44] C.H. Jun, Sang-Ho Lee, Hae-Sang Park, Jeong-Hwa Lee, Use of partial least squares regression for variable selection and quality prediction. 2009 Int. Conf. Comput. Ind. Eng. (2009) 1302-1307. https://doi.org/10.1109/iccie.2009.5223946.

[45] M.J. Bland, D. Altman, Statistical Methods for Assessing Agreement Between Two Methods of Clinical Measurement, Lancet 327 (1986) 307-310, https://doi.org/10 1016/S0140-6736(86)90837-8.

[46] A. Carkeet, Y.T. Goh, Confidence and coverage for Bland-Altman limits of agreement and their approximate confidence intervals, Stat. Methods Med. Res. 27 (2018) 1559-1574, https://doi.org/10.1177/0962280216665419.

[47] E. Arendse, O.A. Fawole, L.S. Magwaza, H. Nieuwoudt, U.L. Opara, Comparing the analytical performance of near and mid infrared spectrometers for evaluating pomegranate juice quality, LWT - Food Sci. Technol. 91 (2018) 180-190, https://doi. org/10.1016/j.lwt.2018.01.035.

[48] C. Sârbu, V. Liteanu, M. Bâldea, Evaluation and validation of analytical methods by regression analysis, Rev. Anal. Chem. 19 (2000) 467-490, https://doi.org/10. 1515/REVAC.2000.19.6.467.

[49] A.P. Filippin, L. Molina Filho, V. Fadel, M.A. Mauro, Thermal intermittent drying of apples and its effects on energy consumption, Dry. Technol. (2018) 1-16, https:// doi.org/10.1080/07373937.2017.1421549.

[50] G. Cuccurullo, L. Giordano, A. Metallo, L. Cinquanta, Drying rate control in microwave assisted processing of sliced apples, Biosyst. Eng. 170 (2018) 24-30, https://doi.org/10.1016/j.biosystemseng.2018.03.010.

[51] K. Sacilik, A.K. Elicin, The thin layer drying characteristics of organic apple slices, J. Food Eng. (2006), https://doi.org/10.1016/j.jfoodeng.2005.03.024.

[52] B. Sturm, A.N. Vega, W.C. Hofacker, O. Hensel, Influence of air velocity on drying kinetics and product quality in drying of apples 6-11, 2007.

[53] S.B. Mabrouk, E. Benali, H. Oueslati, Experimental study and numerical modelling of drying characteristics of apple slices, Food Bioprod. Process. 90 (2012) 719-728, https://doi.org/10.1016/j.fbp.2012.02.001.

[54] L. Fernández, C. Castillero, J.M. Aguilera, An application of image analysis to dehydration of apple discs, J. Food Eng. 67 (2005) 185-193, https://doi.org/10. 1016/j.jfoodeng.2004.05.070.

[55] W. Amjad, O. Hensel, A. Munir, A. Esper, B. Sturm, Thermodynamic analysis of drying process in a diagonal-batch dryer developed for batch uniformity using potato slices, J. Food Eng. (2016), https://doi.org/10.1016/j.jfoodeng.2015.09. 004.

[56] D.F. Holderbaum, T. Kon, T. Kudo, M.P. Guerra, Enzymatic browning, polyphenol oxidase activity, and polyphenols in four apple cultivars: dynamics during fruit development, HortScience 45 (2010) 1150-1154.

[57] H. Jaeger, A. Janositz, D. Knorr, The Maillard reaction and its control during food processing. The potential of emerging technologies, Pathol. Biol. (Paris) 58 (2010) 207-213, https://doi.org/10.1016/j.patbio.2009.09.016.

[58] R. Moscetti, B. Sturm, S.O.J. Crichton, W. Amjad, R. Massantini, Postharvest monitoring of organic potato (cv. Anuschka) during hot-air drying using visible-NIR hyperspectral imaging, J. Sci. Food Agric. 98 (2018) 2507-2517, https://doi.org/10.1002/jsfa.8737.

[59] V.R. Sagar, P. Suresh Kumar, Recent advances in drying and dehydration of fruits and vegetables: a review, J. Food Sci. Technol. 47 (2010) 15-26, https://doi.org/ 10.1007/s13197-010-0010-8.

[60] S. Wold, Exponentially weighted moving principal components analysis and projections to latent structures, Chemom. Intell. Lab. Syst. 23 (1994) 149-161, https:// doi.org/10.1016/0169-7439(93)E0075-F.

[61] S. Wold, J. Trygg, A. Berglund, H. Antti, Some recent developments in PLS mod eling, Chemom. Intell. Lab. Syst. 58 (2001) 131-150, https://doi.org/10.1016/ S0169-7439(01)00156-3.

[62] A.A. Eissa, A.A. Khalik, Understanding Color Image Processing by Machine Vision for Biological Materials. Struct. Funct. Food Eng. (2012). https://doi.org/10.5772/ 50796 . 
[63] D. Wu, D.-W. Sun, Colour measurements by computer vision for food quality control - a review, Trends Food Sci. Technol. 29 (2013) 5-20, https://doi.org/10.1016/j. tifs.2012.08.004.

[64] B. Sturm, Einfluss der Führung des Trocknungsprozesses auf den Trocknungsverlauf und die Produkteigenschaften empfindli- cher Biologischer Güter:

Forschungsbericht Agrartechnik 491 des Arbeitskreises Forschung und Lehre der
Max-Eyth Gesellschaft Agr- artechnik, VDI. Zugl.: Kassel, Univ., Diss., 2010.

[65] J.M. Bland, D.G. Altman, Measuring agreement in method comparison studies, Stat. Methods Med. Res. 8 (1999) 135-160, https://doi.org/10.1191/

096228099673819272 . 